\title{
Indirect Spectrophotometric Determination of Cefalexin monohydrate, Ceftriaxone Sodium and Cefotaxim Sodium in Pharmaceuticals Using N- Bromosuccinimde and Evans Blue Dye
}

\author{
Mohamed Th. Aghwan', Elham S. Salih ${ }^{2 *}$ \\ ${ }^{1,2}$ Department of Chemistry, College of Education for Pure Science, University of Mosul, Mosul, Iraq \\ E-mail: ${ }^{1}$ Mohamed.aghwan@gmail.com, ${ }^{2 *}$ altalibee_59@yahoo.com
}

(Received July 21, 2019; Accepted October 24, 2019; Available online September 01, 2020)

DOI: 10.33899/edusj.2019.125959.1009, ( ) 2020, College of Education for Pure Science, University of Mosul.

This is an open access article under the CC BY 4.0 license (http://creativecommons.org/licenses/by/4.0/).

\begin{abstract}
:
An indirect sensitive and selective spectrophotometric method has been developed for the determination of cephalexin monohydrate (CEM) ceftriaxone sodium (CFX) and cefotaxim sodium (CEF) in bulk and pharmaceutical formulation. The method is based on the oxidation of (CEM), $(\mathrm{CFX})$ and $(\mathrm{CEF})$ in hydrochloric acid medium with known excess on N-Bromosuccinimde and subsequent determination of unreacted oxidant by decolorization of Evans blue dye (EB) and measure the absorbance of residual dye at $608 \mathrm{~nm}$. Calibration curves of evans blue dye in the presence of drugs were rectilinear over the ranges 1.0-9.0, 1.0-8.0 and 1.0-9.0 $\mu \mathrm{g} / \mathrm{ml}$ with molar absorptivity $2.75 \times 10^{4}, 9.28 \times 10^{4}$ and $7.81 \times 10^{4} 1 . \mathrm{mol}^{-1} . \mathrm{cm}^{-1}$ and average recoveries $98.97,102.08$ and $100.08 \%$ for CEM, CFX and CEF respectively with RSD of less than $3.29 \%$. The method was free from interference of many excipients and additives commonly found in pharmaceutical formulations. The developed method was successfully applied for determination of the studied drugs in their pharmaceutical formulation resulted in a good agreement with certified value and standard addition procedure.
\end{abstract}

Keywords: Spectrophotometry, Cefalexin, Ceftriaxone, Cefotaxim, Evans Blue Dye.

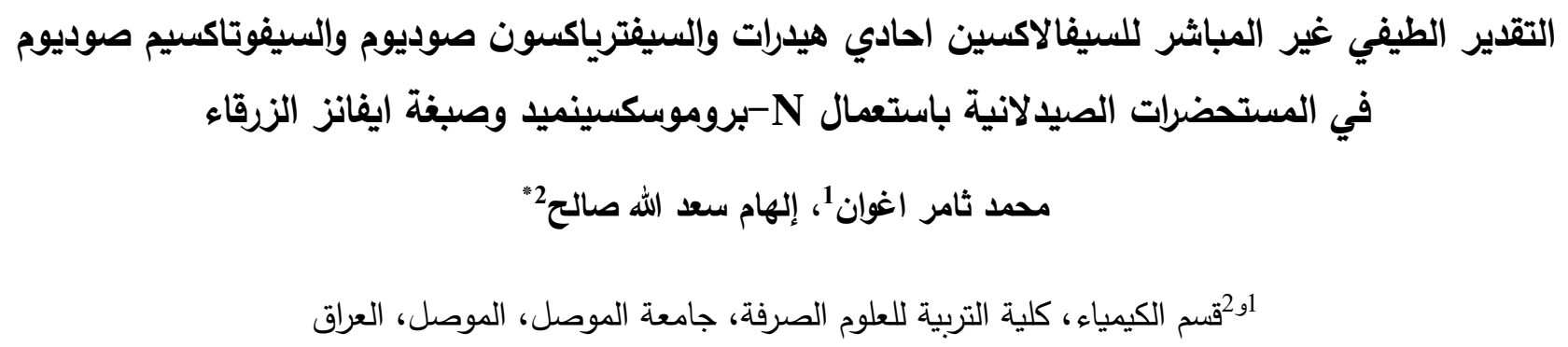

تم تطوير طريقة طيفية غير مباشرة حساسة وانتقائية لتقدير السيفالاكسين احادي هيدرات والسيفترياكسون صوديوم

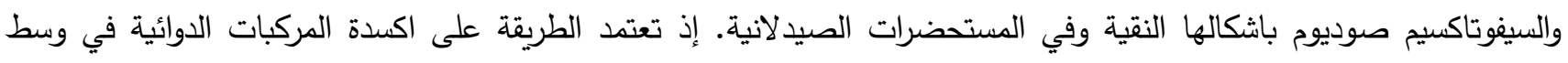
حامض الهيدروكلوريك بزيادة محسوبة من محلول N-بروموسكسينميد ثم تقدير المتبقي من العامل المؤكسد N- بروموسكسينميد 
من خلال قصر لون صبغة ايفانز الزرقاء وقياس امتصاص المتبقي من صبغة ايفانز الزرقاء عند الطول الموجي 608 نانوميتر • إذ إذ

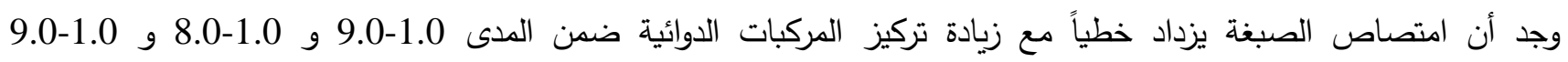

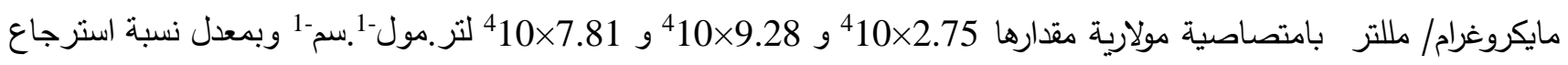
98.97 و 102.08 و 100.08\% لكل من السيفالاكسين هيدرات والسيفترياكسون صوديوم والسيفوتاكسيم صوديوم على التوالي

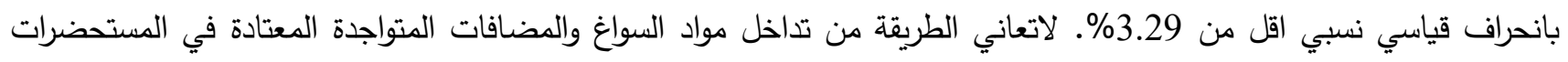

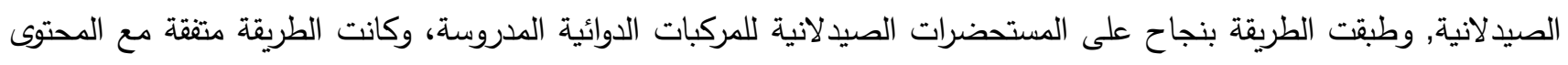
الاصيل للمستحضرات الصيدلانية وطريقة الإضافة القياسية. الكلمات المفتاحية: تقدير طيفي وسيفالاكسين وسيفترياكسون وسيفوتاكسيم وصبغة ايفانز الزرقاء.

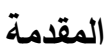

Cefalexin monohydrate السيفالاكسين احادي هيدرات

وهو عبارة عن مشتق نصف مصنع (Semi-synthetic) من السيفالوسبورين وله فعالية مضادة للجراثيم موجبة الكرام

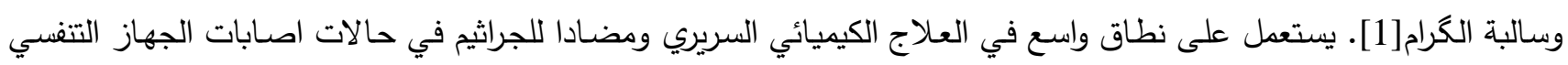

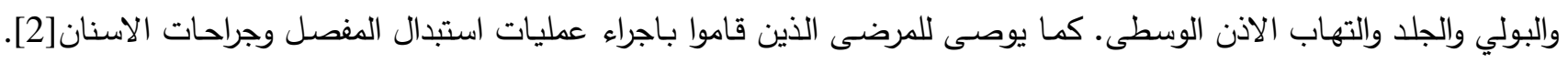<smiles>CC1=C(C(=O)O)N2C(=O)[C@H](NC(=O)[C@H](N)c3ccccc3)[C@H]2SC1</smiles>

$\mathrm{C}_{16} \mathrm{H}_{17} \mathrm{~N}_{3} \mathrm{O}_{4} \mathrm{~S} . \mathrm{H}_{2} \mathrm{O}$

$(6 R, 7 R)$-7-[[(2R)-2-Amino-2-phenylacetyl]amino]-3-methyl-8-oxo-5-thia-1-azabicyclo [4.2.0]oct-2-ene-2-carboxylic acid monohydrate.

Molar mass $=365.4 \mathrm{~g} / \mathrm{mol}$

Ceftriaxone sodium السيفترياكسون صوديوم

يمثل السيفترياكسون الجيل الثالث نصف مصنع من المضاد الحيوي السيفالوسبورين[3] وتظهر فعاليته على مدى واسع من

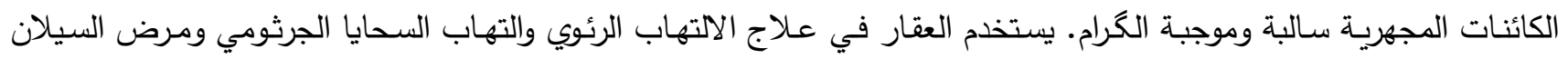

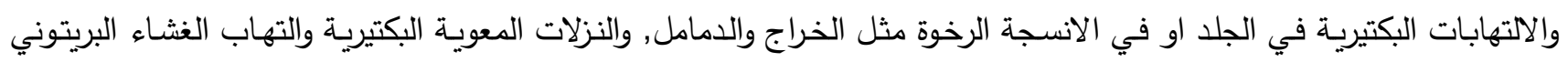

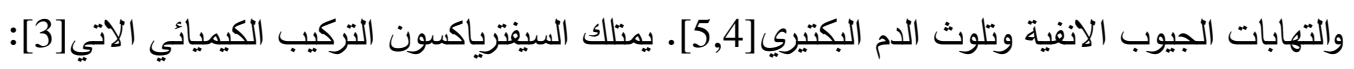<smiles></smiles>

$\mathrm{C}_{18} \mathrm{H}_{16} \mathrm{~N}_{8} \mathrm{Na}_{2} \mathrm{O}_{7} \mathrm{~S}_{3} .3 .5 \mathrm{H}_{2} \mathrm{O}$

sodium $(6 R, 7 R)-7-((E)-2-(2-a m i n o t h i a z o l-4-y l)-2-(m e t h o x y i m i n o) a c e t a m i d o)-3-(((2-m e t h y l-6-o x i d o-5-$ oxo-2,5-dihydro-1,2,4-triazin-3-yl)thio)methyl)-8-oxo-5-thia-1-azabicyclo[4.2.0]oct-2-ene-2-carboxylate

Molar mass $=662 \mathrm{~g} / \mathrm{mol}$ 


\section{Cefotaxime sodium السيفوتاكسيم صوديوم}

يعد السيفوتاكسيم صـوديوم الجيل الثالث من المضـاد الحيوي السيفالوسبورين. يستخدم بشكل رئيسي في علاج الاصـابات الجرثوميـة للجلد والـدماغ والمعدة والانسـة الرخـوة والمجـاري البوليـة والمجـاري التنفسية والجيوب الانفيـة والاذن والتهـاب العظم والمفاصل, فضلاً عن دوره في علاج السيلان والزهري وحمى التيفوئيد[7,6].ويمتلك العقار التركيب الكيميائي الاتي[3]:<smiles>CO/N=C(\C(=O)N[C@H]1C(=O)N2C(C(=O)O[Na])=C(COC(C)=O)CS[C@H]12)c1csc(N)n1</smiles>

\section{$\mathrm{C}_{16} \mathrm{H}_{16} \mathrm{~N}_{5} \mathrm{NaO}_{7} \mathrm{~S}_{2}$}

sodium $(6 R, 7 R)-3-($ acetoxymethyl)-7-((E)-2-(2-aminothiazol-4-yl)-2-(methoxyimino)acetamido)-8-oxo-5Molar mass $=$ thia-1-azabicyclo[4.2.0]oct-2-ene-2-carboxylate

$477.4 \mathrm{~g} / \mathrm{mol}$

استعملت طر ائق تحليلية مختلفة لتقدير المركبات الدوائية قيد الدر اسة، وفيما يأتي مر اجعة لبعض هذه الطر ائق.

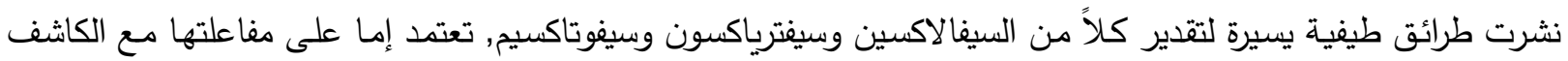
الكروموجيني 2,1-نفثوكوينون-4-سلفونات (NQS) في وسط قاعدي لتكوين نواتج ذوات لون برتقالي تقاس عند اطوال موجية

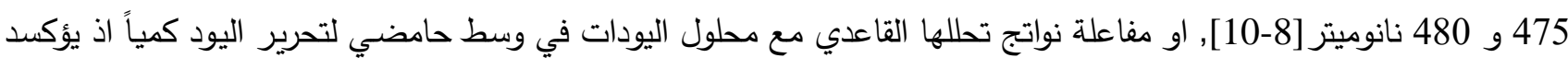

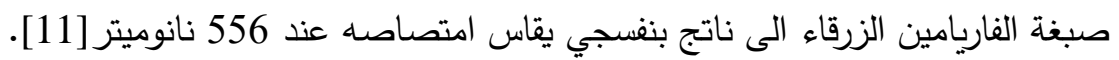

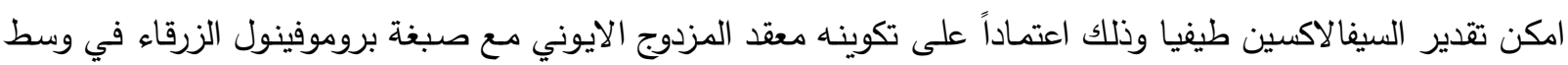

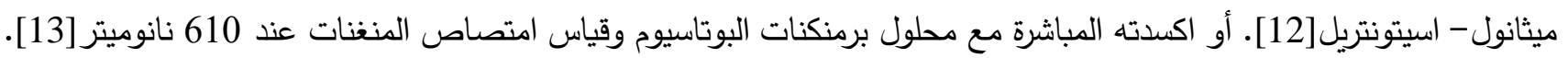

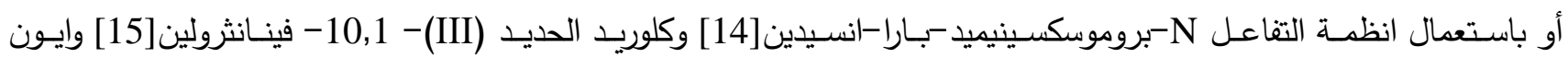
السيريوم(IV) - صبغة المثيل البرتقالي[2] والقياس عند الاطوال الموجية 522 و 510 و 570 نانوميتر على التوالي. وطبقت

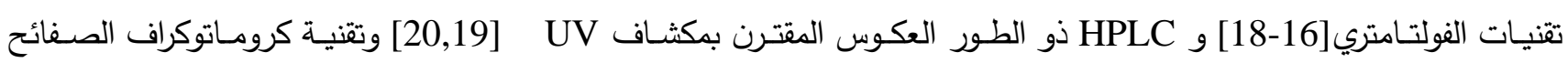
الرقيقة [21]لتحليل السيفالاكسين في المستحضرات الصيدلانية.

وصفت تفاعلات الازوته والاقتران في التقدير الطيفي للسيفترياكسون صوديوم في وذلك إما من خلال ازوتته واقترانه مع م- م-

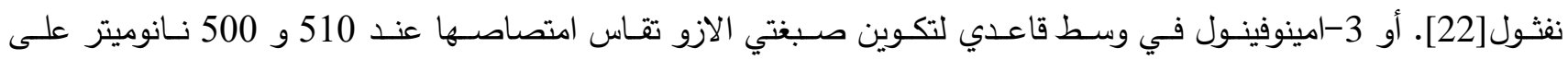

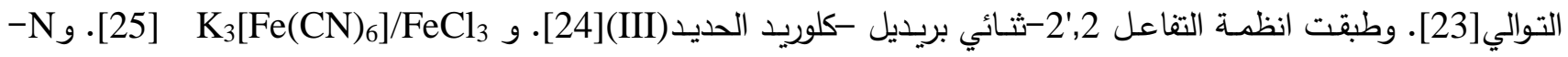
بروموسكسينميد-صبغة الرودامين-B B [26] في التقدير الطيفي غير المباشر اللسيفترياكسون صوديوم. كما امكن تحليل المركب الدوائي في عينات مختلفة بتطبيق تقنيات البريق الكيميائي -الحقن الجرياني[27] وفولتامتري النبضي التفاضلي والحلقي[28] الكهربائية-المنطقة الشعرية[29] وHPLC ذو الطور العكوس المقترن بمكثاف 31,30]UV] او HPLC- المزدوج الايوني[32]. وقدرت كميات مايكروغرامية من سيفوتاكسيم الصوديوم طيفياً في مستحضراته الصيدلانية اعتماداً على تكوينه إما معقدات الثحنة المنتقلة نوع n- مـع محلول اليود في وسط ثنائي كلوروميثان ونوع n-n مع المستقبلات حامض الكلورانيليك وDDQ

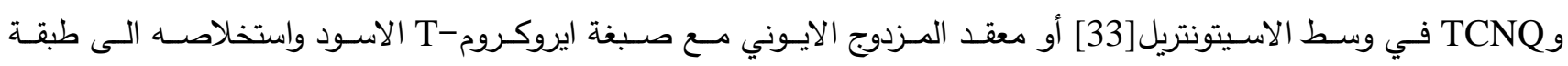
الكلوروفورم[34]. وقدر العقار تفلورياً من خلال اخماده لتفلور صبغة 7,2- ثنائي كلورو فلوريسين أو تعكيرياً بالاقتران مع الحقن 


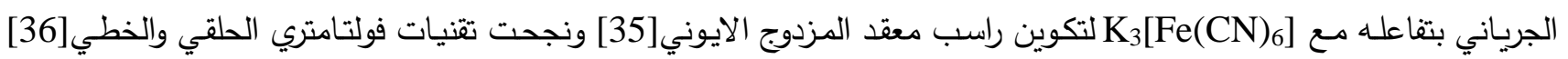
وطبقت تقنيـة HPLC المقترن بمكثـاف 38,37]UV او مطيـاف الكتلـة[39] في تحليـل المركب الدوائي في المستحضـرات الصيدلانية والعينات الحيوية.

\section{Evans blue dye صغة الايفانز الزرقاء}

الايفانز الزرقاء هي صبغة ازوية وتدعى ايضـا Direct blue 53 تكون بشكل مسحوق ازرق غامق وذات درجة ذوبان

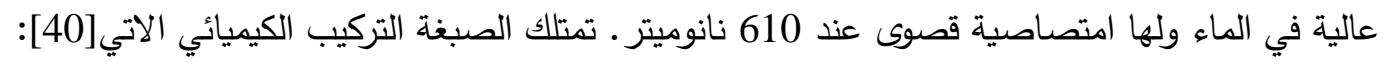<smiles>Cc1cc(-c2ccc(N=Nc3ccc4c(S(=O)(=O)O)cc(S(=O)(=O)O[Na])c(N)c4c3O)c(C)c2)ccc1N=Nc1ccc2c(S(=O)(=O)O)cc(S(=O)(=O)O)c(N)c2c1O</smiles>

tetrasodium (6E,6'E)-6,6-[(3,3'-dimethylbiphenyl-4,4'-diyl)di(1E)hydrazin-2-yl-1-ylidene]bis(4-amino-5-oxo-5,6(dihydronaphthalene-1,3-disulfonate

Molar mass $=960.81 \mathrm{~g} / \mathrm{mol}$

إن لصبغة ايفانز الزرقاء تاريخ طويل باعتبارها صبغة حيوية وعامل تثخيصي سريري منذ استخدامها لاول مرة في عام 1914م من قبل عالم التشريح Herbert McLean Evans. وبسبب ذوبانها العالي في الماء, وبطء طرحها خارج الجسم وارتباطها الوثيق بزلال المصل (البومين المصل) فانها استعملت على نطاق واسع في مجال الطب الحياتي عند تقدير حجم الدم Blood)

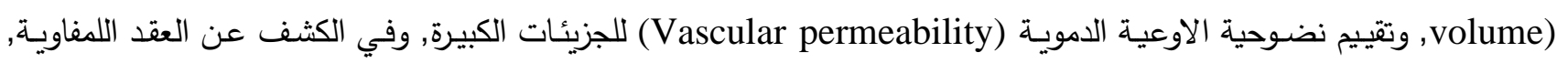
وتحديد مواقع اصـابات الاورام[41]. وان لصبغة الايفانز الزرقاء ميل للخلايا الميتة او المصـابة بالنخر (Necrosis) وذلكك لان لان

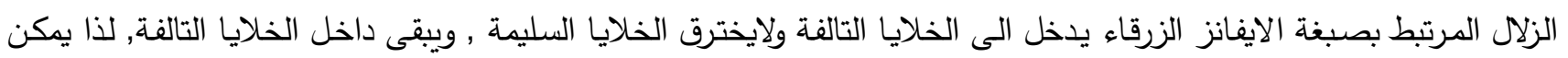
استخدام الصبغة في تقييم حيوية الانسجة[42]. استخدمت صبغة الايفانز الزرقاء بوصفها كاشفاً كروموجينياً في تطوير طرائق لونية يسيرة وسريعة وحساسة في التقدير

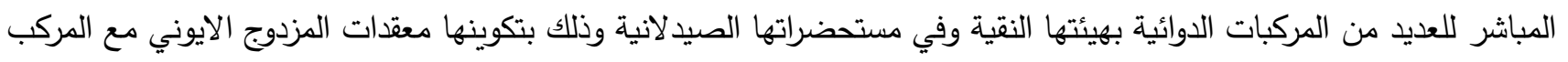

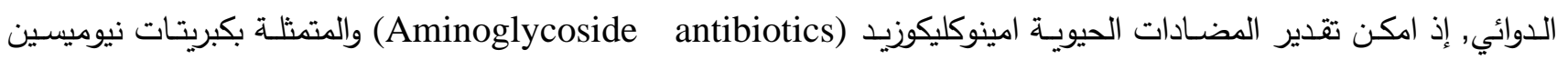
7- وكاناميسين والجنتاميسين وثوبراميسين وذلك إما بقياس امتصاصات المزدوجات الايونية المتكونة في وسط منظم دالته الحامضية التئ

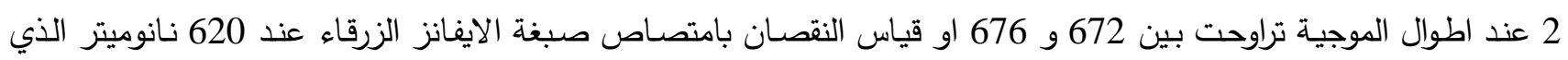

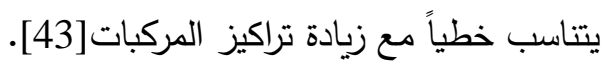
كما امكن تقدير العقار رالوكسيفين (Raloxifene) بمفاعلته مع صبغة الايفانز الزرقاء في وسط محلول خلات الصوديومي حامض الهيدروكلوريك المنظم (pH 1.4-2.5) وتكوين معقد المزدوج الايوني[نسئ (44). ونظراً لاهمية الصبغة ووفرتها وعدم وجود طرائق طيفية تعتمد في تقدير المركبات الدوائية على استعمال نظام التفاعل صبغة لغنة

الايفانز الزرقاء -العامل المؤكسد لذا يهدف البحث الى استحداث طريقة يسيرة ودقيقة وحساسة لتقدير عدد من مضادات الحيوية

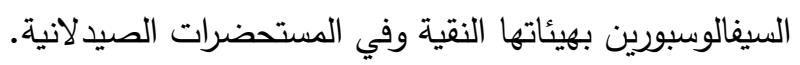
الجزء العملي الأجهزة المستعملة

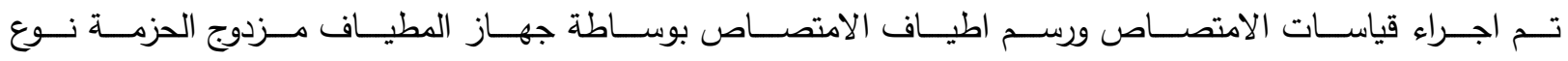
باستخدام خلايا الكوارتز ذات السمك 1سم . Shimadzu UV-1800 PC, UV-Visible double-Spectrophotometer 


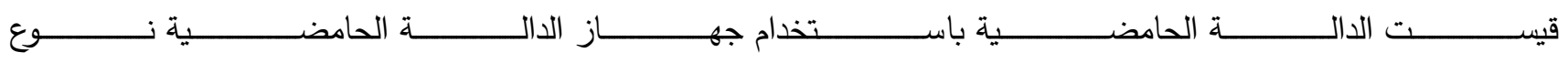
Thermo RL 060P Electron Company-Singapore باستخدام ميزان حساس نوع KERN ABS-Germany. تمت عمليات التسخين بوساطة حمام مائي نوع BS-11. . Lab Companion-Korea .Lab Tech-Korea مجز من شركة Power Sonic 405

\section{الكواشف والمواد الكيميائية المستخدمة \\ محاليل المواد المستعملة}

1- محاليـل السيفالاكسـين احـادي هيـدرات والسيفترياكسـون صـوديوم والسيفوتاكسـيم صـوديوم تحضـر المحاليـل بتركيز 50 مايكروغرام/مللتر وذلك باذابة 0.0100 غرام من المركبات الدوائية قيد الدراسة بصيغتها النقية في 200 مللتر من الماء المقطر

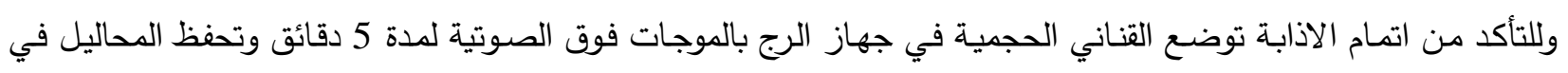
الثلاجة وتبقى مستقرة لمدة اسبوع. - محلول N-بروموسكسينميد يحضر بتركيز 100 مايكروغرام/ملتر باذابة 0.0100 غرام من المركب في 100 مللتر من الماء المقطر ويبقى مستقراً لمدة اسبوع واحد في الثلاجة. 3- محلول الكلورامبن-T يحضر بتركيز 200 مايكروغرام/مللتر باذابة 0.0200 غرام من المركب في 100 مللتر من الماء المقطر يحفظ في الثلاجة ويبقى مستقراً لمدة اسبوع واحد. 4- محلول برومات - بروميد يحضر محلول اولي بتركيز 0.002 مولاري برومات البوتاسيوم مع 0.02 مولاري بروميد البوتاسيوم

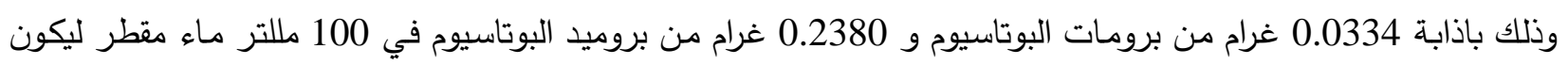

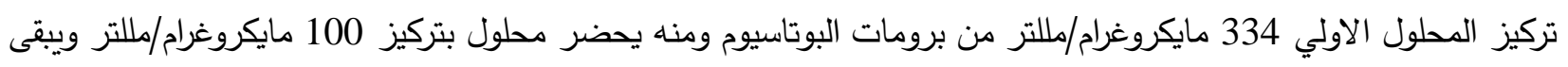

$$
\text { مستقراً لمدة اسبوع واحد. }
$$

5- محلول صبغة ايفانز الزرقاء يحضر المحلول بتركيز 100 مايكروغرام/مللتر باذابة 0.025 غرام من الصبغة في 250 مللتر

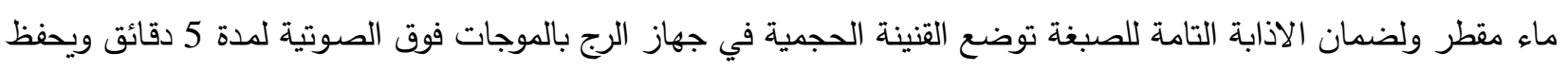

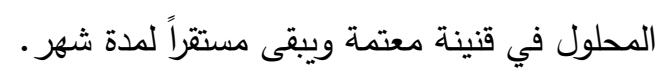
6- محلول حامض الهيدروكلوريك يحضر محلول حامض الهيدروكلوريك بتركيز 2 مولاري بتخفيف 50 ملتر من الحامض المركز

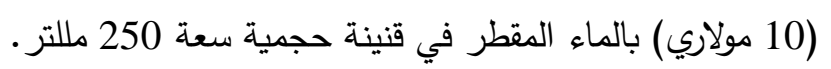

7- محاليل المتداخلات تحضر بتركيز 1000 مايكروغرام/ ملتر بإذابة 0.1000 غرام منها في 100 مللتر من الماء المقطر . طريقة العمل اضيفت الى مجموعة من قنان حجمية سعة 10 مللتر حجوم متزايدة (مللترات) من محاليل المركبات الدوائية المدروسـة

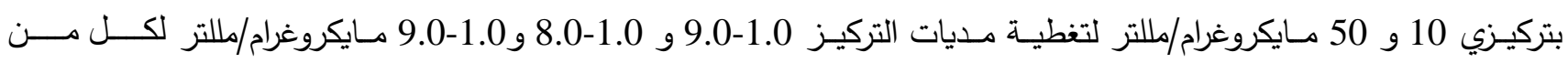
السيفالاكسين هيدرات والسيفترياكسون والسيفوتاكسيم صوديوم على التوالي والكميات المثالية من حامض الهيدروكلوريك بتركيز 2

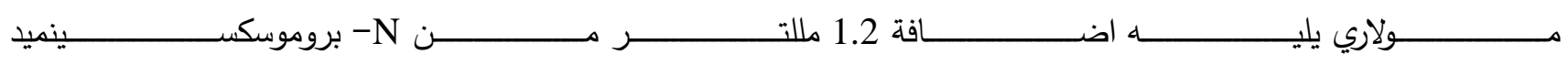
(100 ماكروغرام/مللتر) وتترك المحاليل لمدة 10 دقائق مع الرج, ثم يتبعها اضـافة 2.5 مللتر من محلول صبغة ايفانز الزرقاء

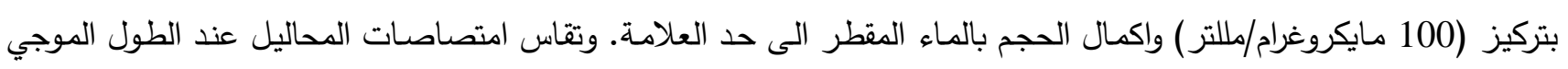

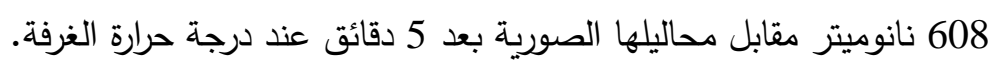


تحليل كبسول السيفالاكسين احادي هيدرات

وزن محتوى 10 كبسولات بدقة من كل مستحضر دوائي (Cefex Capsules Micro Labs Limited India) Cephadar Forte Capsules Dar Al Dawa , Na'ur - Jordan (500 ملغرام من السيفالاكسين) ثم اذيب بالماء المقطر واكمل الحجم الى حد العلامة في قنينة حجمية سعتها 500 مللتر • رشح المحلول بعد الرج في جهاز الرج بالموجات فوق الصوتية لمدة 5 دقائق ليتم الحصول على ملى محلول تركيزه 1000 مايكروغرام/ملتر

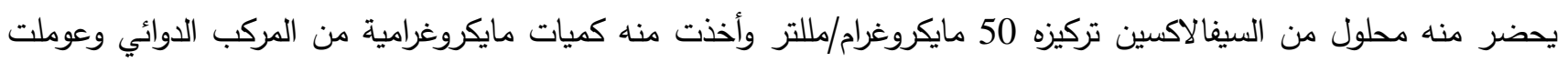
على وفق طريقة العمل الموصوفة. وتم إيجاد تركيز السيفالاكسين في قرص كل مستحضر دوائي من المنحني القياسي للسيفالاكسين

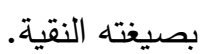

تحليل حقن السيفترياكسون صوديوم

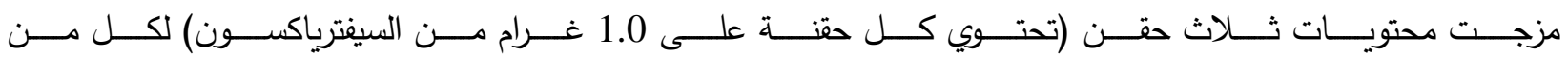

Ceftriaxone Laboratorios Torlan, S.A.Ctra Barcelona Spain) المستحضـرين الـدوائيين و Triaxone Tabuk Pharmaceutical Saudi Arabia) ثم وزن بدقة مايعادل حقنة واحدة اذيب واكمل الحجم بالماء المقطر

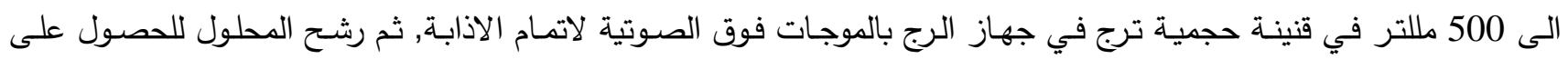
السيفترياكسون بتركيز 2000 مايكروغرام/مللتر ثم حضر منه محلول بتركيز 50 مايكروغرام/مللتر وأخذت منه كميات مايكروغرامية من المركب الدوائي وعوملت على وفق طريقة العمل الموصوفة. وتم إيجاد تركيز السيفترياكسون صوديوم في كل مستحضر دوريز دائي من المنحني القياسي للسيفترياكسون بصيغته النقية.

تحليل حقن السيفوتاكسيم صوديوم

تم مزج محتويات ثلاث حقن لكل من الانموذجين الدوائيي(Brucitaz Brawn laboratories limited India و Deforan Deva Holding A,S Turkey الحجم الى حد العلامة في قنينة حجمية سعة 500 مللتر , ثم رشح المحلول بعد الرج بالموجات فوق الصوتية للحصول على التركيز 2000 مايكروغرام/مللتر وحضر منه محلول بتركيز 50 مايكروغرام/مللتر وأخذت منه كميات مايكروغرامية من المركب الدوائي وعوملت على وفق طريقة العمل الموصوفة. وتم ايجاد تركيز السيفوتاكسيم باستعمال المنحنى القياسي للمركب الدوائي بصيغته النقية.

النتائج والمناقشة

الاراسة التمهيدية وطيف امتصاص صبغة ايفانز الزرقاء

بغية تطوير طريقة طيفية يسيرة وحساسـة لتقدير المركبات الدوائية المدروسـة اجريت تجارب اولية لبيان امكانية استخدام

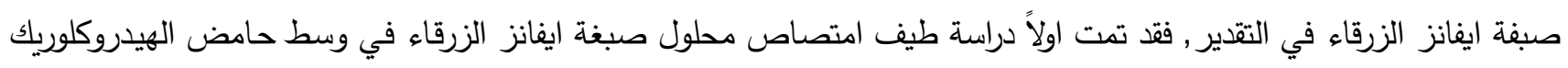

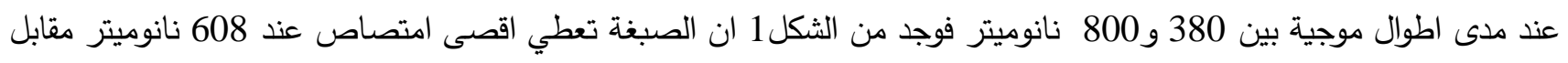
المحلول الصوري.

وثانيا وجد تجريبياً حدوث اكسدة كمية لصبغة ايفانز الزرقاء بوساطة كميات مايكروغرامية من محاليل العوامل المؤكسدة

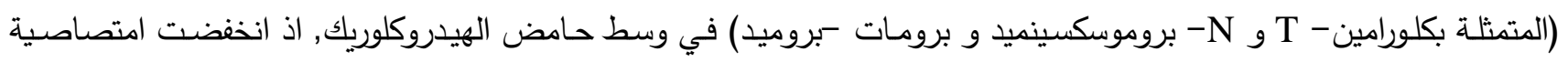
الصبغة بزيادة تركيز العامل المؤكسد وذلك من خلال قصر لونها. وبالاعتماد على هذه الخصيصة درس امكانية التقدير الطيفي 
غير المباشر للمركبات الدوائية المدروسـة (السيفالاكسين والسيفترياكسون والسيفوتاكسيم) إذ تمت اكسدة كميات مايكروغرامية من

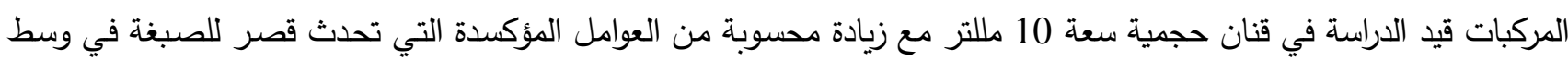
حامض الهيدروكلوريك. وتركت المحاليل 5 دقائق مع الرج بدرجة حرارة الغرفة, واضيفت بعدها كمية ثابتة من صبغة فئة ايفانز الزرقاء

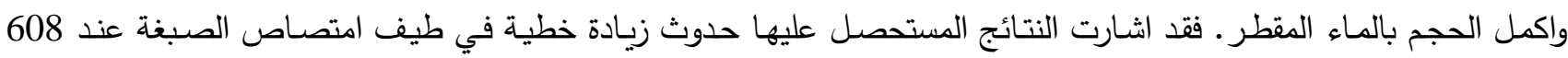
نانوميتر بزيادة تركيز المركب الدوائي, او بمعنى اخر ان تركيز العامل المؤكسد يقل بزيادة تركيز المركب الدوائي مؤديا الى ظهور

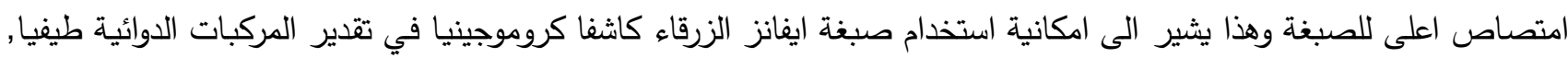
الثكل 1.

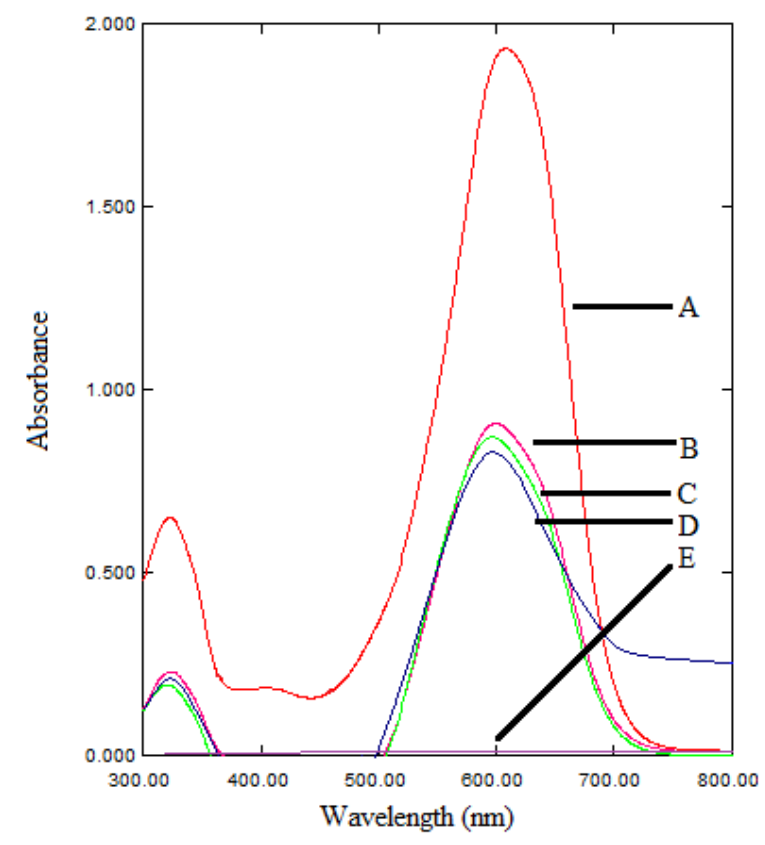

الثكل 1: اطياف امتصاص صبغة ايفانز الزرقاء (25 مايكروغرام/مللتر) في وسط حامضي (A) (A), وعند تقدير السيفالكسين

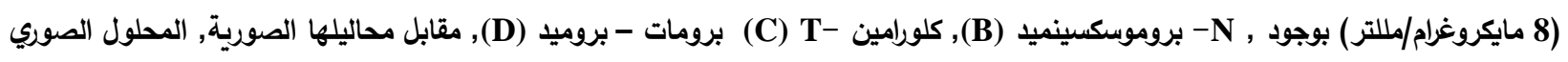
مقابل الماء المقطر (E)

ضبط الظروف المثلى لتقدير المركبات الدوائية أجريت التجارب التالية في قنانٍ حجمية سعة 10 ملتر بوجود 1.6 مللتر بتركيز 50 مايكروغرام/مللتر من محاليل المركبات

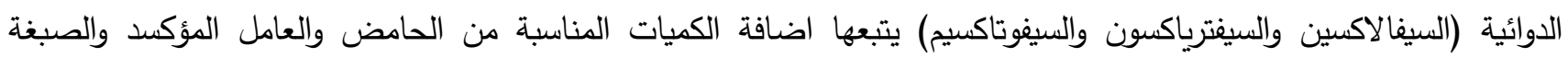
وقياس امتصاص صبغة ايفانز الزرقاء عند 608 نانوميتر • 2 دراسة كمية صبغة ايفانز الزرقاء لتحديد الكمية المثلى من صبغة ايفانز الزرقاء التي يمكن استخدامها في تقدير المركبات الدوائية المدروسة والتي تطيع قانون

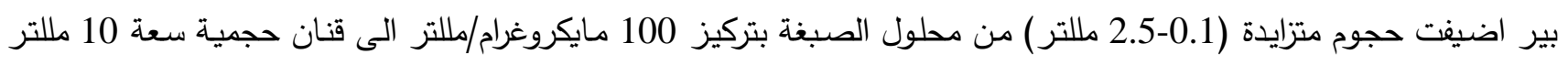

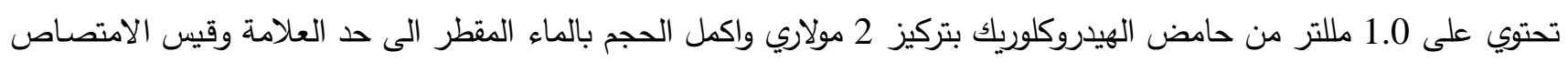
عند 608 نانوميتر , فوجد من النتائج المبينة في الثكل 2 ان مدى التركيز الخطي لصبغة ايفانز الزرقاء وعليه ثبت التركيز 25 مايكروغرام/مللتر للتقدير في الدراسات اللاحقة. 


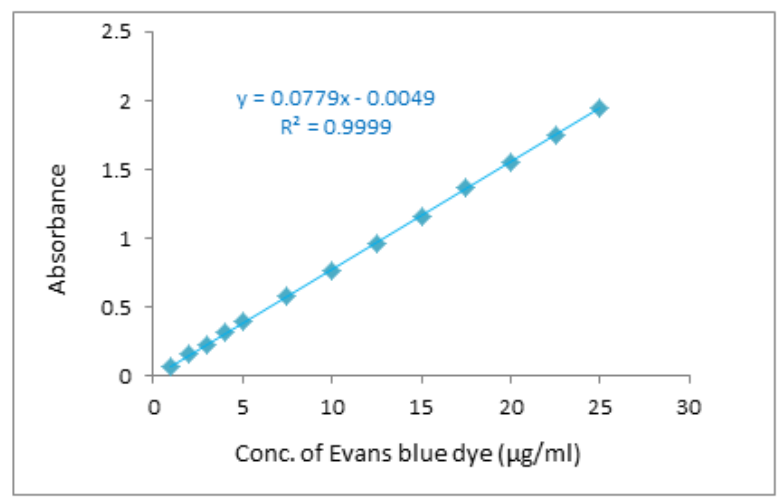

الثكل 2: المنحنى القياسي لصبغة ايفانز الزرقاء

تاثير نوع المذيب في امتصاص صبغة ايفانز الزرقاء

من اجل الحصول على افضل مذيب يعطي اقصى امتصاص لصبغة ايفانز الزرقاء , فقد تم دراسة تاثيره على كل من ذوبانية

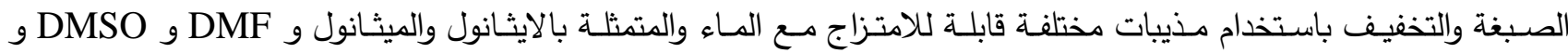
لاسيتونتريل فضلاً عن الماء وذلك باضافة 2.5 مللتر من محلول صبغة ايفانز الزرقاء بتركيز 100 مايكروغرام/ملتر الى قنان حجمية 10 مللتر تحتوي على 1.0 مللتر حامض الهيدروكلوريك (2 مولاري) و 3.5 مللتر من الماء المقطر ثم اكمل الحجم الى حد العلامة بالمذيب وقيست امتصاصات المحاليل مقابل محاليلها الصورية. وتبين من النتائج التي تم الحصول عليها من الشكل 3 أن الاذابة والتخفيف بالماء المقطر أعطى اقصى امتصاص للصبغة لذلك تم اعتماده في الدراسات اللاحقة.

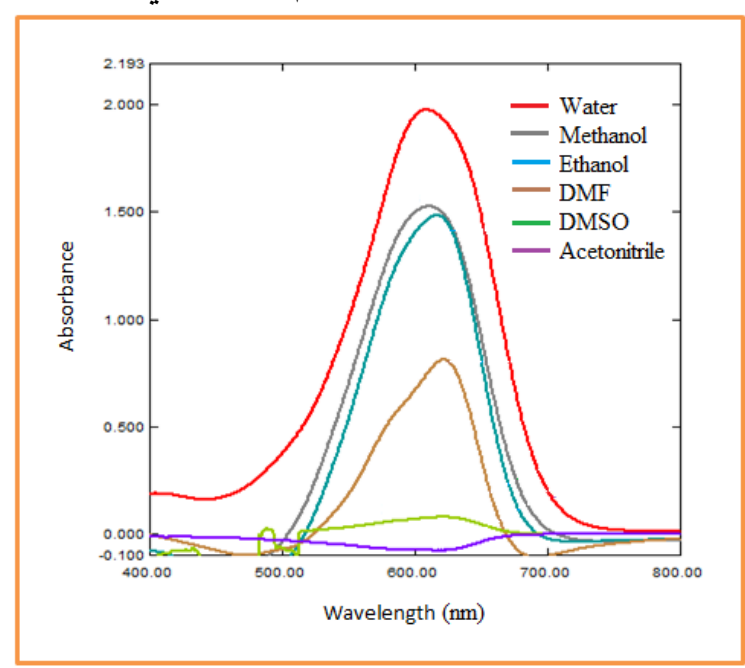

الثكل 3: اطياف امتصاص صبغة ايفانز الزرقاء (25 مايكروغرام/ملتر)

تاثير كمية العامل المؤكسد في قصر لون صبغة ايفانز الزرقاء

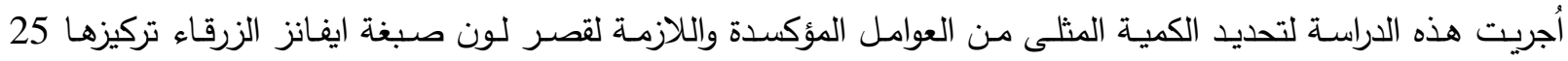
مايكروغرام/مللتر وذلك اعتماداً على مفاعلتها مع كميات مايكروغرامية من محاليل كلورامين - T بتركيز (200 مايكروغرام/ملتر ) و

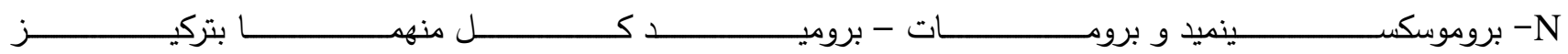

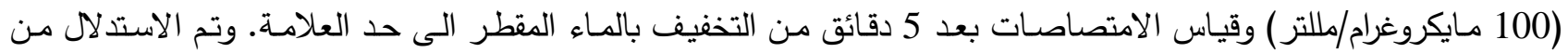
المنحنيات القياسية في الثكل 4 ان التراكيز المثلى التي تطيع قانون بير واللازمة لقصر صبغة ايفانز الزرقاء لكل من محاليل 
كلورامين - T و N - بروموسكسينميد و برومات- بروميد كانت 40 و 12 و10 مايكروغرام/مللتر على التوالي وعليه اعتمدت في الدراسات اللاحقة لاكسدة المركبات الدوائية الدروسة.

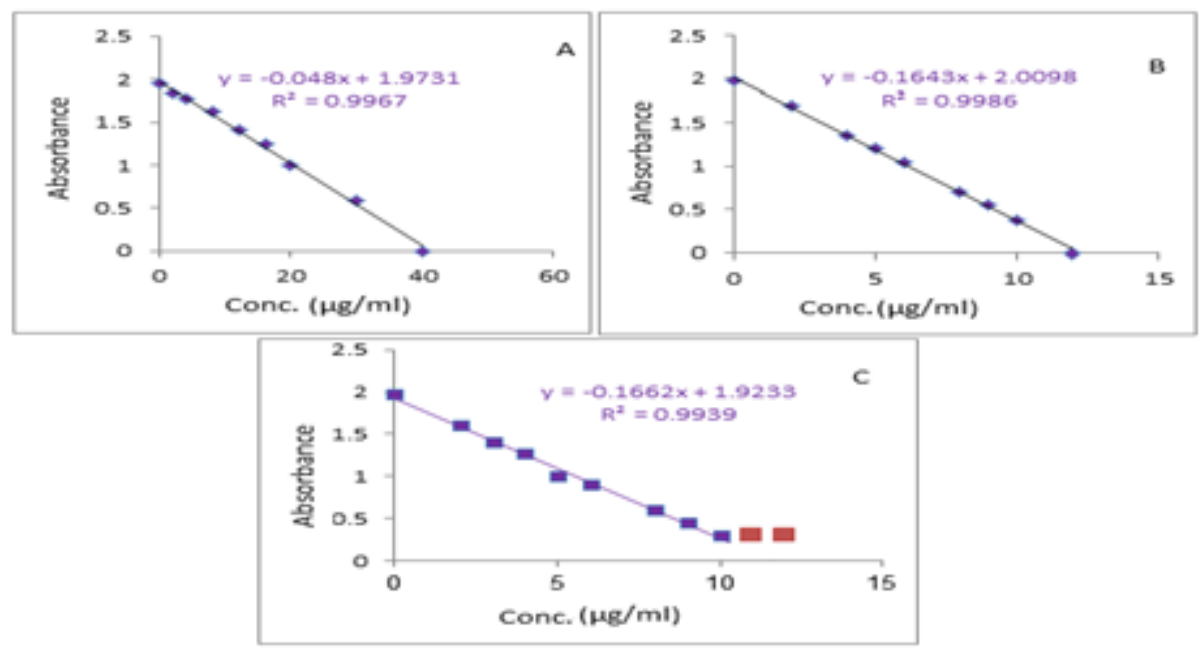

الثكل 4: المنحنيات القياسية لاختيار كمية العامل المؤكسد في قصر 25 مايكروغرام/مللتر من صبغة ايفانز الزرقاء في الوسط الحامضي.

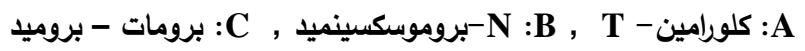

اختيار العامل المؤكسد للمركبات الدوائية المدروسة

تمت دراسة تاثير العوامل المؤكسدة كلورامين - N T بروموسكسينميد وبرومات- بروميد بكمياتها المحسوبة كلا على

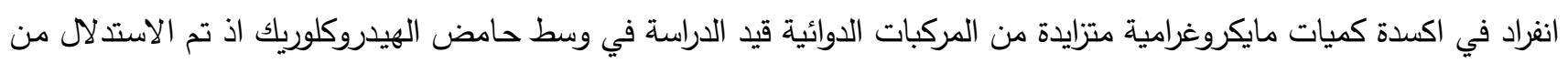

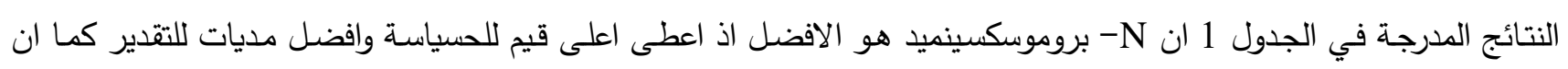

معامل الارتباط كان ممتازا وعليه اعتمد في الدراسات اللاحقة.

الجدول 1: اختيار العامل المؤكسد لتقدير المركبات الدوائية المدروسة

\begin{tabular}{|c|c|c|c|c|}
\hline \multirow{2}{*}{ 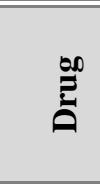 } & \multirow{2}{*}{ Parameter } & \multicolumn{3}{|c|}{ Oxidizing agent $(\mu \mathrm{g} / \mathrm{ml})$} \\
\hline & & $\begin{array}{c}\text { Chloramin-T } \\
(40 \mu \mathrm{g} / \mathrm{ml})\end{array}$ & $\begin{array}{c}\text { N-bromosuccinimide } \\
(12 \mu \mathrm{g} / \mathrm{ml})\end{array}$ & $\begin{array}{c}\text { Bromate - bromide } \\
(10 \mu \mathrm{g} / \mathrm{ml})\end{array}$ \\
\hline \multirow{3}{*}{ 离 } & Linearity range $(\mu \mathrm{g} / \mathrm{ml})$ & $3.0-11.0$ & $1.0-9.0$ & $2.0-7.0$ \\
\hline & $\begin{array}{c}\varepsilon \max \\
\left(\mathrm{L} \cdot \mathrm{mol}^{-1} . \mathrm{cm}^{-1}\right)\end{array}$ & $1.9 \times 10^{4}$ & $2.7 \times 10^{4}$ & $2.4 \times 10^{4}$ \\
\hline & $\mathrm{R}^{2}$ & 0.9998 & 0.9995 & 0.9970 \\
\hline \multirow{3}{*}{ 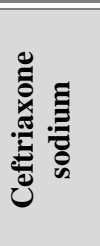 } & Linearity range $(\mu \mathrm{g} / \mathrm{ml})$ & $1.0-5.0$ & $1.0-8.0$ & $2.5-9.0$ \\
\hline & $\begin{array}{c}\varepsilon \max \\
\left(\mathrm{L} \cdot \mathrm{mol}^{-1} \cdot \mathrm{cm}^{-1}\right)\end{array}$ & $8.8 \times 10^{4}$ & $9.2 \times 10^{4}$ & $6.6 \times 10^{4}$ \\
\hline & $\mathrm{R}^{2}$ & 0.9930 & 0.9993 & 0.9960 \\
\hline \multirow{3}{*}{ 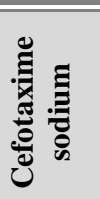 } & Linearity range $(\mu \mathrm{g} / \mathrm{ml})$ & $4.5-10.0$ & $1.0-9.0$ & $1.0-6.0$ \\
\hline & $\begin{array}{c}\varepsilon \max \\
\left(\mathrm{L} \cdot \mathrm{mol}^{-1} \cdot \mathrm{cm}^{-1}\right)\end{array}$ & $5.7 \times 10^{4}$ & $7.8 \times 10^{4}$ & $4.8 \times 10^{4}$ \\
\hline & $\mathrm{R}^{2}$ & 0.9992 & 0.9997 & 0.9970 \\
\hline
\end{tabular}


اختيار الحامض المناسب

اثتت النتائج العملية التي اجريت ان أكسدة صبغة ايفانز الزرقاء والمركبات الدوائية المدروسة بوساطة N- بروموسكسينميد

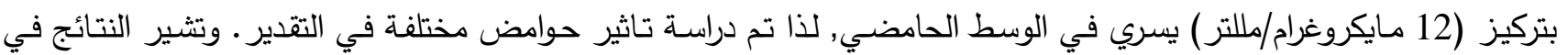
الجدول ان التركيز 2 مـلاري اعطى اعلى امتصـاص لذلك تم استعماله في تفاعل الاكسدة للصبغة والمركبات الدوائيسة وذلك بالحصول على اعلى امتصاص, وعليه اعتمد في الدراسات اللاحقة.

الجدول 2: اختيار الحامض المناسب وسطأ في تقدير المركبات الدوائية

\begin{tabular}{|c|c|c|c|c|c|}
\hline \multirow[b]{2}{*}{ Drug $(8 \mu \mathrm{g} / \mathrm{ml})$} & \multicolumn{5}{|c|}{ Absorbance* } \\
\hline & $\mathrm{HCl}$ & $\mathrm{H}_{2} \mathrm{SO}_{4}$ & $\mathrm{H}_{3} \mathrm{PO}_{4}$ & $\mathrm{HNO}_{3}$ & $\mathrm{CH}_{3} \mathrm{COOH}$ \\
\hline Cefalexin monohydrate & 0.681 & 0.431 & 0.094 & 0.080 & 0.031 \\
\hline Ceftriaxone sodium & 1.101 & 0.347 & 0.146 & 0.124 & 0.025 \\
\hline Cefotaxime sodium & 1.183 & 0.541 & 0.130 & 0.154 & 0.027 \\
\hline
\end{tabular}

*1.0ml of $2 \mathrm{M}$ acid added

تاثير كمية حامض الهيدروكلوريك

تم الاستدلال من الدراسة في الجدول 3 والتي اجريت لتثبيت تركيز حامض الهيدروكلوريك بالاعتماد على اضافة 1.0 مللتر من الحامض ضمن مدى التراكيز 0.5-5.0 مولاري, ان التركيز 2 مولاري هو الانسب في تقدير جميع المركبات الدوائية المدروسة. الجدول 3: تاثير تركيز حامض الهيدروكلوريك في التقدير

\begin{tabular}{|c|c|c|c|}
\hline \multirow[b]{2}{*}{ Molarity of $\mathrm{HCl}^{*}$} & \multicolumn{3}{|c|}{ Absorbance/ $8 \mu \mathrm{g} / \mathrm{ml}$ drug } \\
\hline & $\begin{array}{c}\text { Cefalexin } \\
\text { monohydrate }\end{array}$ & Ceftriaxone sodium & Cefotaxime sodium \\
\hline 0.5 & 0.581 & 0.934 & 0.974 \\
\hline 1 & 0.662 & 0.942 & 1.074 \\
\hline 2 & 0.683 & 1.102 & 1.188 \\
\hline 3 & 0.680 & 1.100 & 1.186 \\
\hline 4 & 0.680 & 1.099 & 1.185 \\
\hline 5 & 0.682 & 1.099 & 1.182 \\
\hline
\end{tabular}

*1.0ml of $(\mathrm{X}) \mathrm{MHCl}$

كما اجريت دراسة لبيان تاثير حجوم متزايدة (0.5-2.5 مللتر) من محلول حامض الهيدروكلوريك (2 مولاري), اذ اشارت النتائج المستحصلة في الثكل5 ان الحجوم المثلى المعتمدة في الدراسات اللاحقة هي 1.5 مللتر عند تقدير السيفالاكسين و2.0 ملتر عند عند تقدير السيفترياكسون والسيفوتاكسيم. 


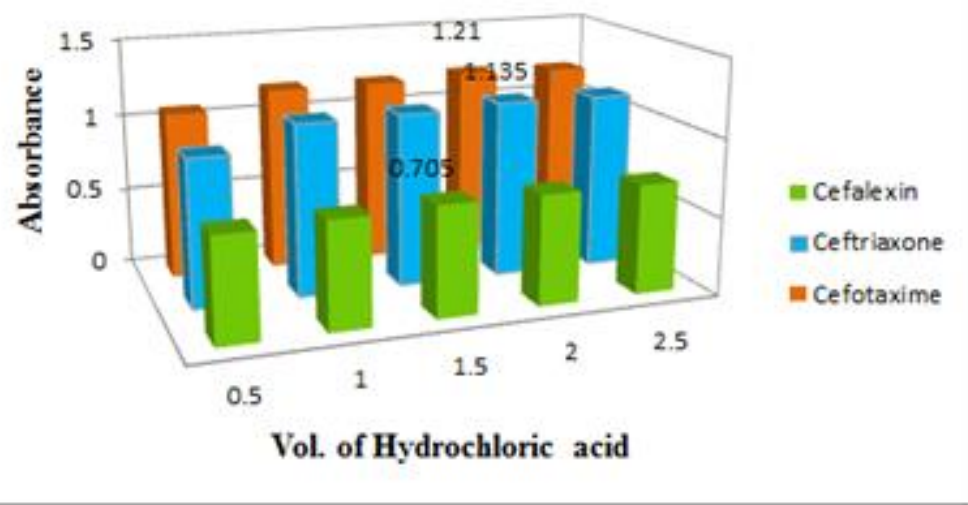

الثكل 5: تاثير كمية حامض الهيدروكلوريك في تقدير المركبات الدوائية المدروسة

تأثير الزمن في أكسدة المركبات الدوائية حُدد في هذه الدراسة الزمن اللازم لأكسدة المركبات الدوائية المدروسة وصبغة اليفانز الزرقاء والصبغة عند درجات حرارة الغرفة، إذ يبين الجدول 4 أن 10 دقائق فترة زمنية كافية لأكسدة السيفالاكسين بوصفه أنموذجاً، و5 دقائق لأكسدة صبغة الزيفة الزانز الزرقاء، وهذه الأزمنة مناسبة لأكسدة وتقدير السيفترياكسون والسيفوتاكسيم صوديوم.

الجدول 4: تأثير الزمن في أكسدة السيفالاكسين (8 مايكروغرام/ ملتر) بوصفه أنموذجاً

\begin{tabular}{|c|c|c|c|c|c|c|c|c|c|}
\hline \multirow{2}{*}{$\begin{array}{c}\text { Standing time } \\
\text { before adding EB \& } \\
\text { dilution (min) }\end{array}$} & \multicolumn{9}{|c|}{ Absorbance/ standing time after adding EB \& dilution (min) } \\
\hline & 5 & 10 & 20 & 30 & 40 & 50 & 60 & 120 & $\begin{array}{c}\text { Over } \\
\text { night }\end{array}$ \\
\hline After addition & 0.584 & 0.584 & 0.585 & 0.589 & 0.591 & 0.592 & 0.593 & 0.597 & 0.583 \\
\hline 5 & 0.641 & 0.639 & 0.640 & 0.641 & 0.641 & 0.640 & 0.639 & 0.637 & 0.639 \\
\hline 10 & 0.767 & 0.765 & 0.766 & 0.765 & 0.764 & 0.764 & 0.765 & 0.765 & 0.763 \\
\hline 15 & 0.742 & 0.741 & 0.741 & 0.742 & 0.743 & 0.740 & 0.740 & 0.738 & 0.740 \\
\hline 20 & 0.732 & 0.731 & 0.729 & 0.728 & 0.728 & 0.729 & 0.728 & 0.727 & 0.725 \\
\hline
\end{tabular}

تاثير تسلسل الاضافة

تثير النتائج المستحصلة عملياً ان التسلسل المتبع في تثبيت الظروف المثلى للمركبات الدوائيـة ملائم في التقدير , وان حدوث اي تغير في تسلسل الاضافة يؤثر سلبا على التقدير. السيفالاكسين (S + (A) + (A) + بروموسكسينميد (NBS) + صبغة ايفانز الزرقاء (EB) 


\section{طيف الامتصاص النهائي}

رُسمت اطياف الامتصاص النهائية لتقدير المركبات الدوائية المدروسة بعد تثبيت الظروف المثلى للتفاعل وذلك بإضافة الكميات المثلى من محاليل العامل المؤكسد والحامض وصبغة ايفانز الزرقاء في قناني حجمية 10 ملتر وقياس الامتصاصات عند 608 نانوميتر كما مبين في الشكل 6.

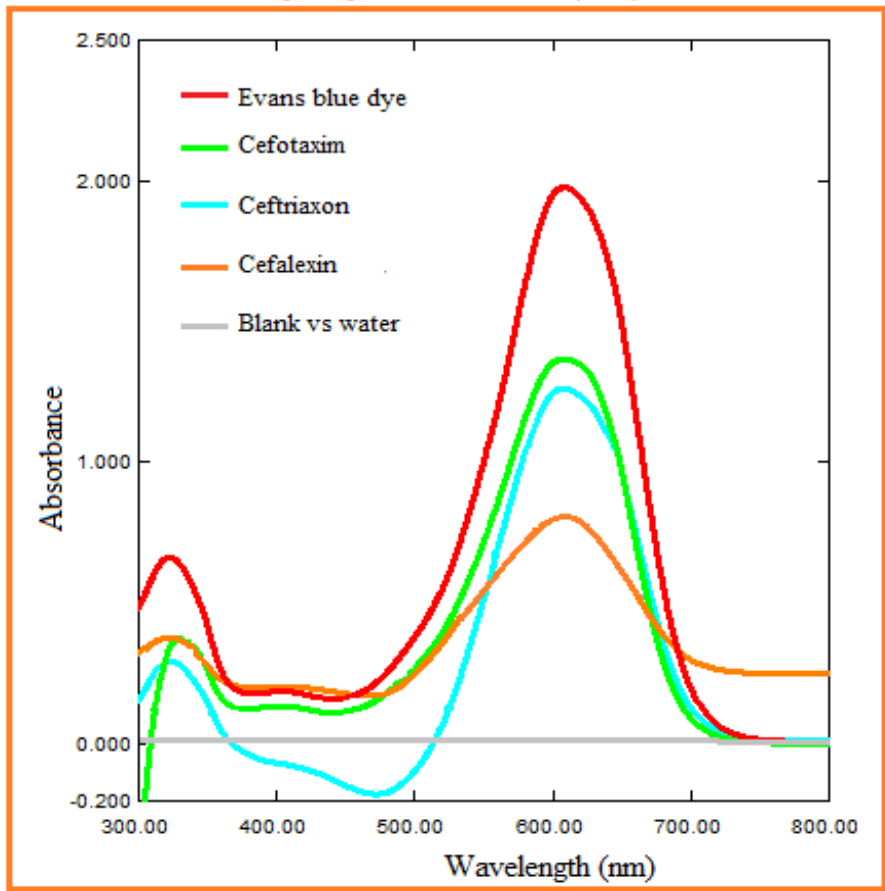

الثكل 6: أطياف الامتصاص لمحلول صبغة ايفانز الزرقاء (25 مايكروغرام/مللتر) لوحدها أو بوجود (8 مايكروغرام/ملتر) من الأدوية المقدرة في وسط التفاعل

\section{القيم الاحصائية وحساسية الطريقة المقترحة}

من خلال رسم المنحنيات القياسية لتقدير السيفالاكسين احادي هيدرات والسيفترياكسون صوديوم والسيفوتاكسيم صوديوم

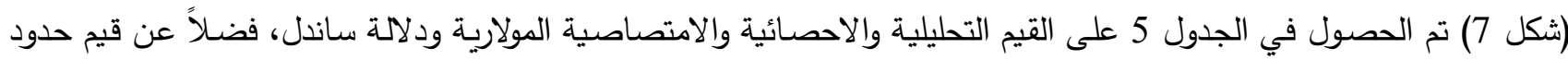
الكثف والتقدير الكمي التي حسبت بأخذ عشرة مكررات لاقل تركيز وقياس الامتصاص مقابل الماء المقطر وتطبيق المعادلات

$$
\mathrm{LOD}=\frac{3 \sigma \mathrm{C}_{\text {low }}}{\bar{X}} \quad \cdot \quad \mathrm{LOQ}=\frac{10 \sigma \mathrm{C}_{\text {low }}}{\bar{X}}
$$


Journal of Education and Science (ISSN 1812-125X), Vol: 29, No: 3, 2020 (11-31)

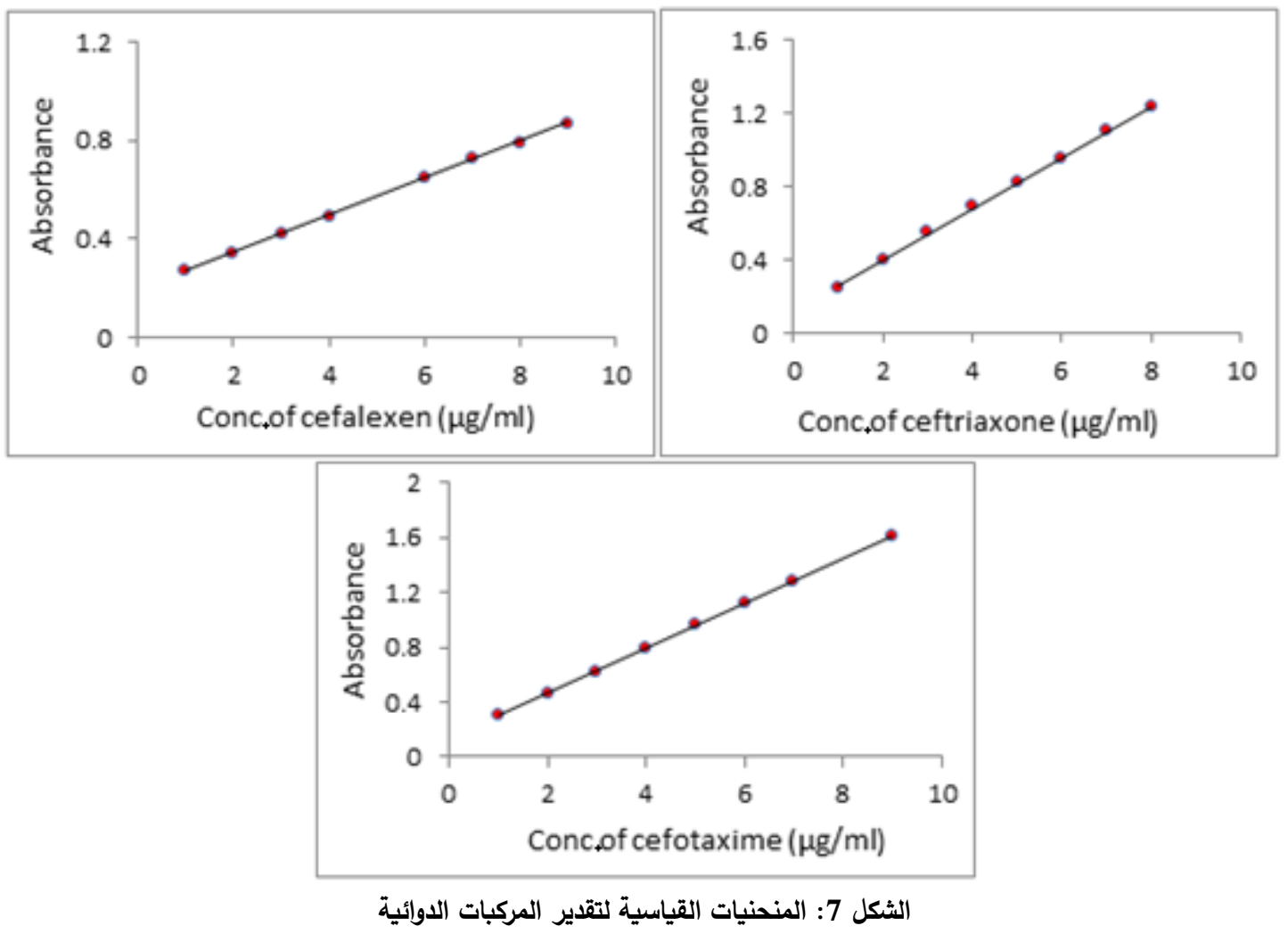

الجدول 5: القيم التحليلية الاحصائية للمنحنيات القياسية والامتصاصية المولارية وحدود الكثف والتقدير الكمي في تقدير المركبات الدوائية قيد الدراسة

\begin{tabular}{|c|c|c|c|}
\hline Parameter & Cefalexin & Ceftriaxone & Cefotaxime \\
\hline Linearity range $(\mu \mathrm{g} / \mathrm{ml})$ & $1.0-9.0$ & $1.0-8.0$ & $1.0-9.0$ \\
\hline Intercept & 0.1927 & 0.1193 & 0.1373 \\
\hline Slope & 0.0753 & 0.1402 & 0.1637 \\
\hline Correlation coefficient $\left(\mathbf{R}^{2}\right)$ & 0.9995 & 0.9993 & 0.9997 \\
\hline Standard deviation of the intercept & 0.0037 & 0.0074 & 0.0056 \\
\hline Standard deviation of the slope & 0.0006 & 0.0014 & 0.0010 \\
\hline $\begin{array}{c}\text { Molar absorptivity } \\
\left(\text { l.mol }^{-1} . \mathbf{c m}\right)\end{array}$ & $2.75 \times 10^{4}$ & $9.28 \times 10^{4}$ & $7.81 \times 10^{4}$ \\
\hline Sandell Sensitivity $\left(\mathbf{n g} / \mathrm{cm}^{2}\right)$ & 13.29 & 7.06 & 6.11 \\
\hline LOD* $(\mu \mathrm{g} / \mathrm{ml})$ & 0.023 & 0.019 & 0.014 \\
\hline $\mathrm{LOQ}^{*}(\mu \mathrm{g} / \mathrm{ml})$ & 0.079 & 0.063 & 0.047 \\
\hline
\end{tabular}

*Average of ten determinations of $\mathrm{C}_{\text {low }}$ of drug 
دقة الطربقة وتوافقها اختبرت دقة الطريقة وتوافقها بحساب نسب الاسترجاع والانحراف القياسي النسبي لأربعة تراكيز مختلفة لكل مركب دوائي ودونت النتائج في الجدول6 التي تشير إلى دقة الطريقة وتوافقها.

الجدول 6: دقة الطريقة وتوافقها لتقدير المركبات الدوائية

\begin{tabular}{|c|c|c|c|c|c|}
\hline \multirow{2}{*}{ Drug } & \multicolumn{2}{|c|}{ Conc of drug $(\mu \mathrm{g} / \mathrm{ml})$} & \multirow{2}{*}{ Recovery* $(\%)$} & \multirow{2}{*}{$\begin{array}{c}\text { Average } \\
\text { recovery }(\%)\end{array}$} & \multirow{2}{*}{ RSD* $(\%)$} \\
\hline & Taken & Found & & & \\
\hline \multirow{3}{*}{$\begin{array}{c}\text { Cefalexin } \\
\text { monohydrate }\end{array}$} & 2 & 1.95 & 97.50 & \multirow{3}{*}{98.97} & 2.18 \\
\hline & 4 & 3.95 & 98.75 & & 1.22 \\
\hline & 6 & 6.04 & 100.66 & & 3.29 \\
\hline \multirow{3}{*}{ Ceftriaxon sodium } & 2 & 1.99 & 99.50 & \multirow{3}{*}{102.08} & 1.50 \\
\hline & 4 & 4.09 & 102.25 & & 2.29 \\
\hline & 6 & 6.27 & 104.50 & & 1.27 \\
\hline \multirow{3}{*}{$\begin{array}{c}\text { Cefotaxime } \\
\text { sodium }\end{array}$} & 2 & 1.96 & 98.00 & \multirow{3}{*}{100.08} & 2.12 \\
\hline & 4 & 4.01 & 100.25 & & 2.07 \\
\hline & 6 & 6.12 & 102.00 & & 3.08 \\
\hline
\end{tabular}

*Average of six determinations.

التفاعل الكيميائي المقترح

استتاداً الى ميكانيكية التفاعلات والدراسات الحركية المنشورة في الادبيات العلمية فان N- بروموسكسينميد يعد عاملاً مؤكسداً

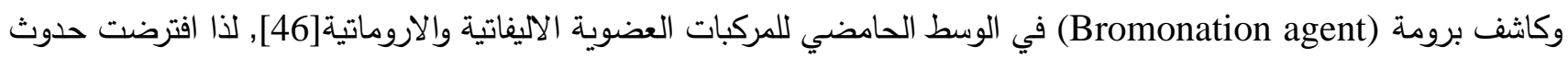

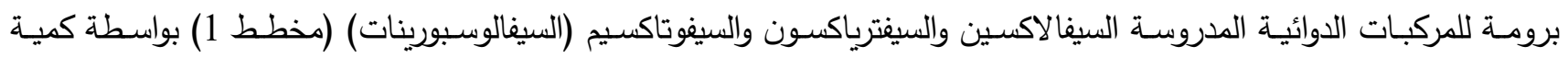
محسوبة من N-بروموسكسينميد في وسط حامض الهيدروكلوريك ليتبعها تقدير الكمية المتبقية من محلول العامل المؤكسد من خلال

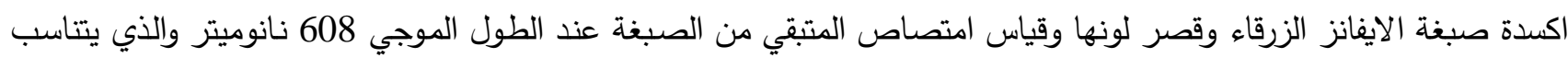

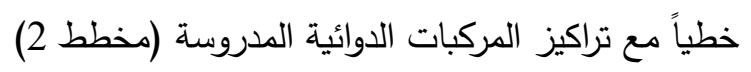



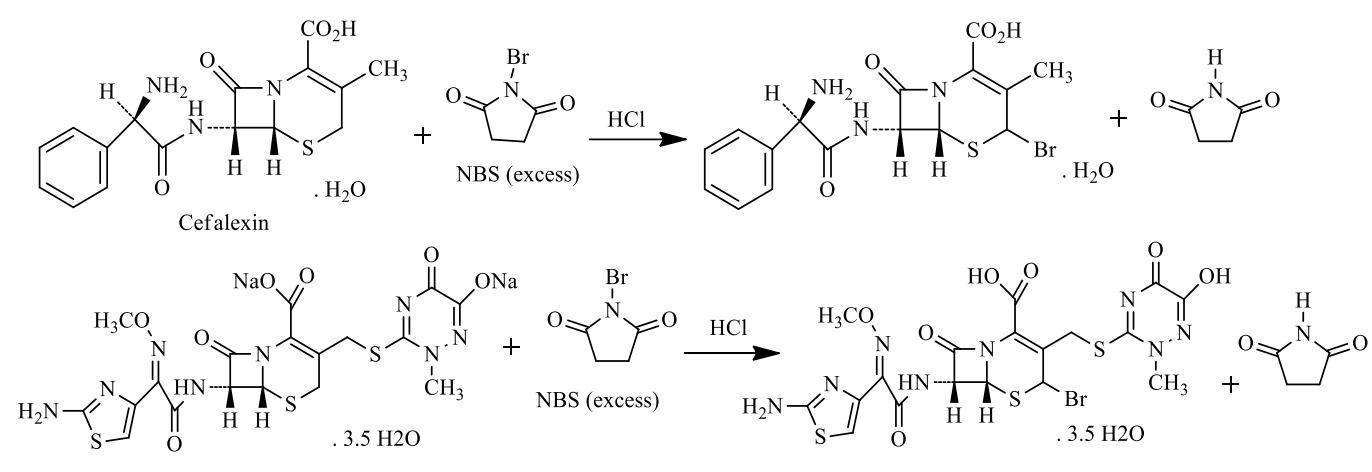

Ceftriaxone

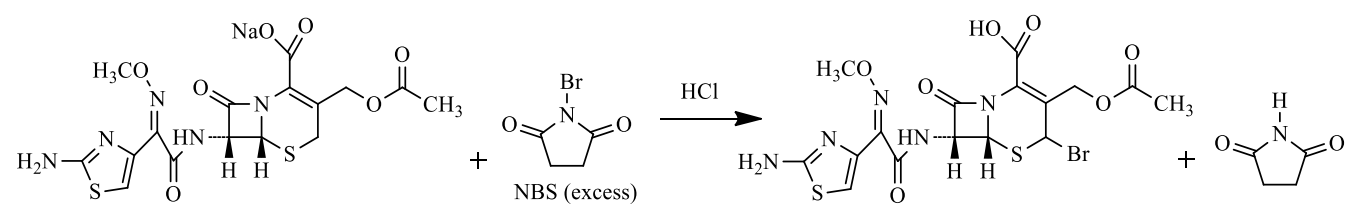

Cefotaxim

(المخطط 1)

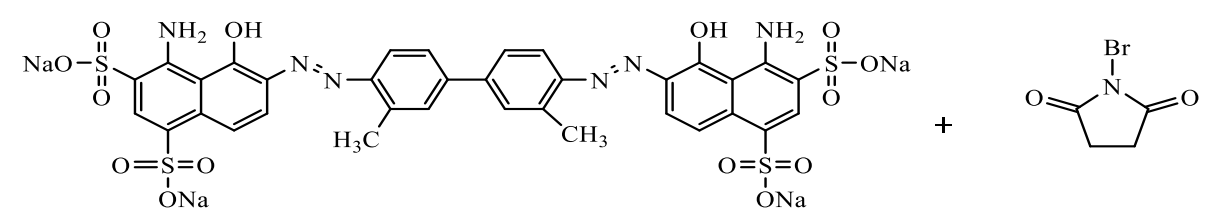

Evans blue colored

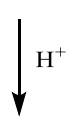

NBS (unreacted)

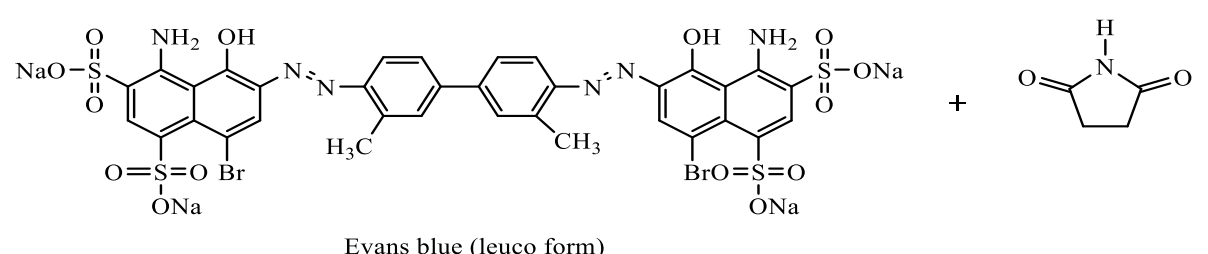

(المخطط 2) 
تأثير المتداخلات

درس تاثير بعض مواد السّواغ والمضافات الدوائية والاملاح بهدف امكانية تطبيق الطريقة الطيفية المطورة على المستحضرات الصيدلانية. وتبين من الجدول7 انتقائية الطريقة في تقدير السيفالاكسين بوصفه انموذجاً لبقية المركبات الدوائية المدروسة وملاءمة تطبيقها على المستحضرات الصيدلانية لعدم حدوث تداخل يمكن ان تحدثه هذه المواد على اعتبار ان نسبة

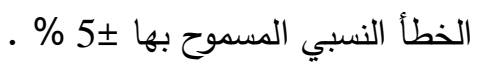

الجدول 7: أثير المتداخلات

\begin{tabular}{|c|c|c|c|c|}
\hline \multirow[t]{2}{*}{ Foreign compound } & \multicolumn{4}{|c|}{$\begin{array}{c}\text { Recovery (\%) of } 80 \mu \mathrm{g} \text { Cefalexin per } \mu \mathrm{g} \text { of foreign } \\
\text { compound added }\end{array}$} \\
\hline & 100 & 250 & 500 & 1000 \\
\hline Glucose & 101.43 & 101.98 & 102.27 & 103.51 \\
\hline Fructose & 100.75 & 101.10 & 102.51 & 103.28 \\
\hline Lactose & 99.53 & 100.63 & 101.98 & 102.51 \\
\hline Sucrose & 98.67 & 99.11 & 99.90 & 101.32 \\
\hline Accacia & 100.37 & 100.95 & 101.47 & 102.95 \\
\hline Saccharin & 98.56 & 100.27 & 101.18 & 102.95 \\
\hline Starch & 100.25 & 101.71 & 102.11 & 104.48 \\
\hline Sodium chloride & 97,32 & 99.97 & 101.30 & 102.89 \\
\hline Potassium chloride & 99.67 & 101.01 & 102.28 & 102.91 \\
\hline Magnesium carbonate & 100.30 & 101.19 & 101.78 & 103.61 \\
\hline
\end{tabular}

تطبيق الطريقة المطورة على المستحضرات الصيدلانية طبقت الطريقة المطورة لتقدير المركبات الدوائية (السيفالاكسين احادي هيدرت والسيفترياكسون صوديوم والسيفوتاكسيم صوديوم) في مستحضراتها الصيدلانية والتي كانت بشكل كبسولات وحقن والمصنعة من مناشئ مختلفة كما مشار اليها في الجدول 
Journal of Education and Science (ISSN 1812-125X), Vol: 29, No: 3, 2020 (11-31)

\begin{tabular}{|c|c|c|c|c|c|}
\hline Pharmaceutical preparation & $\begin{array}{l}\text { Certified } \\
\text { value }\end{array}$ & $\begin{array}{c}\text { Amount } \\
\text { present } \\
(\mu \mathrm{g} / \mathrm{ml})\end{array}$ & $\begin{array}{l}\text { Drug content } \\
\text { found* } \\
\text { (mg or g) }\end{array}$ & Recovery* (\%) & $\begin{array}{c}\text { Average } \\
\text { recovery } \\
(\%)\end{array}$ \\
\hline \multicolumn{6}{|c|}{ Cefalexin monohydrate } \\
\hline \multirow{4}{*}{ Cefex Capsules India } & \multirow{4}{*}{$500 \mathrm{mg}$} & 2 & 515.85 & 103.17 & \multirow{4}{*}{101.29} \\
\hline & & 3 & 515.50 & 103.10 & \\
\hline & & 5 & 492.25 & 98.45 & \\
\hline & & 8 & 502.15 & 100.43 & \\
\hline \multirow{4}{*}{$\begin{array}{c}\text { Cephadar Forte Capsules } \\
\text { Jordan }\end{array}$} & \multirow{4}{*}{$500 \mathrm{mg}$} & 2 & 502.60 & 100.52 & \multirow{4}{*}{100.77} \\
\hline & & 3 & 507.25 & 101.45 & \\
\hline & & 5 & 497.75 & 99.55 & \\
\hline & & 8 & 507.80 & 101.56 & \\
\hline \multicolumn{6}{|c|}{ Ceftriaxone sodium } \\
\hline \multirow{4}{*}{ Ceftriaxone vial spain } & \multirow{4}{*}{$1 \mathrm{~g}$} & 2 & 1.0288 & 102.88 & \multirow{4}{*}{101.18} \\
\hline & & 3 & 1.0115 & 101.15 & \\
\hline & & 5 & 0.9951 & 99.51 & \\
\hline & & 7 & 1.0118 & 101.18 & \\
\hline \multirow{4}{*}{ Triaxone vial Saudi Arabia } & \multirow{4}{*}{$1 \mathrm{~g}$} & 2 & 1.0146 & 101.46 & \multirow{4}{*}{101.26} \\
\hline & & 3 & 1.0204 & 102.04 & \\
\hline & & 5 & 0.9975 & 99.75 & \\
\hline & & 7 & 1.0179 & 101.79 & \\
\hline \multicolumn{6}{|c|}{ Cefotaxim sodium } \\
\hline \multirow{4}{*}{ Brucitaz vial India } & \multirow{4}{*}{$1 \mathrm{~g}$} & 2 & 0.9718 & 97.18 & \multirow{4}{*}{98.75} \\
\hline & & 5 & 1.0057 & 100.57 & \\
\hline & & 6 & 0.9778 & 97.78 & \\
\hline & & 9 & 0.9946 & 99.46 & \\
\hline \multirow{4}{*}{ Deforan vial Turkey } & \multirow{4}{*}{$1 \mathrm{~g}$} & 2 & 0.9625 & 96.25 & \multirow{4}{*}{99.28} \\
\hline & & 3 & 1.0026 & 100.26 & \\
\hline & & 6 & 1.0097 & 100.97 & \\
\hline & & 9 & 0.9963 & 99.63 & \\
\hline
\end{tabular}

* Average of five determinations

\section{مقارنة الطريقة المقترحة مع طريقة الاضافة القياسية}

لاثبات كفاءة الطريقة الطيفيـة المقترحسة ونجاحها في تقدير المركبات الدوائيسة المدروسـة وخلوهـا من تداخلات المضـافات

الدوائية في مستحضراتها الصيدلانية فقد تم تطبيق طريقة الاضافة القياسية على المستحضرات الصيدلانية لكل من السيفالاكسين والسيفترياكسون والسيفوتاكسيم بسبب صعوبة تطبيق الطرائق القياسية الواردة في دستور الادويـة البريطاني[3] وذلك لعدم توفر المستلزمات اللازمـة للتطبيق من حيث الاجهزة والمواد الكيميائية. اذ يمكن الاستدلال من الاشكال 8 و 9 و 10 والجدول 9 ان

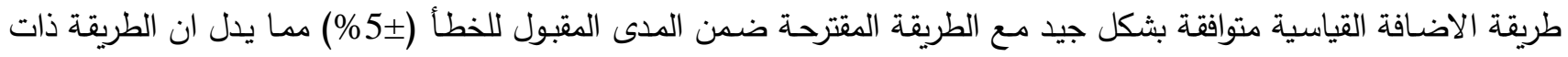
انتقائية بثكل مرض الان 

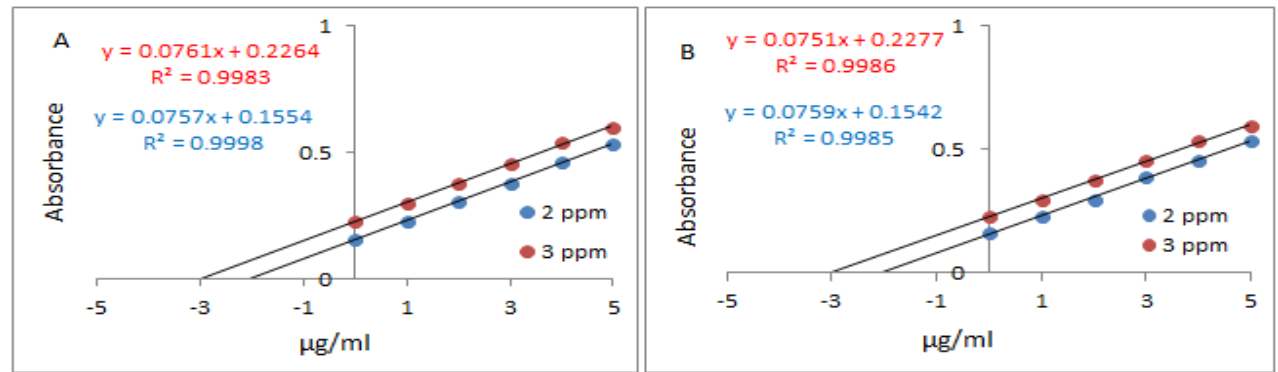

الثكل 8: منحنيات الاضافة القياسية للسيفالكسين احادي هيدرات في مستحضراته الصيدلانية

A : هندي المنشأ B: اردني المنشأ
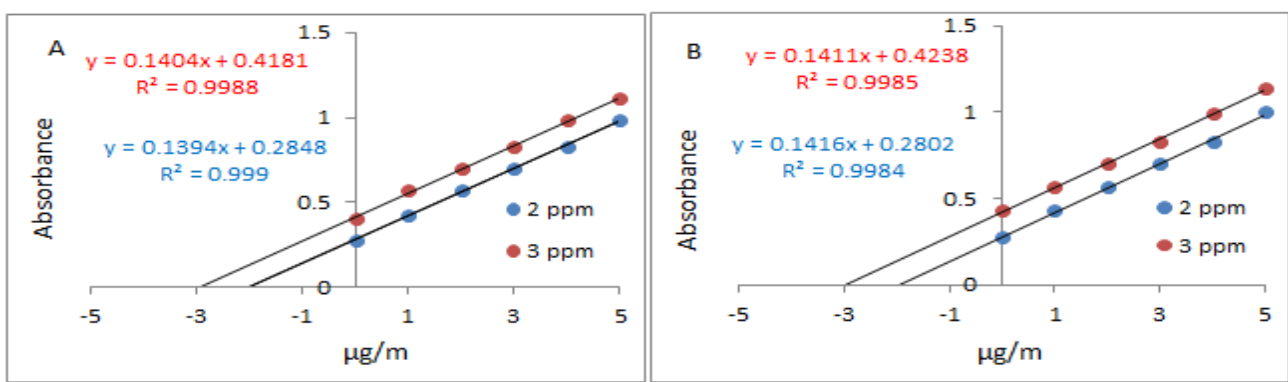

الثكل 9: منحنيات الاضافة القياسية للسيفترياكسون صوديوم في مستحضراته الصيدلانية

A
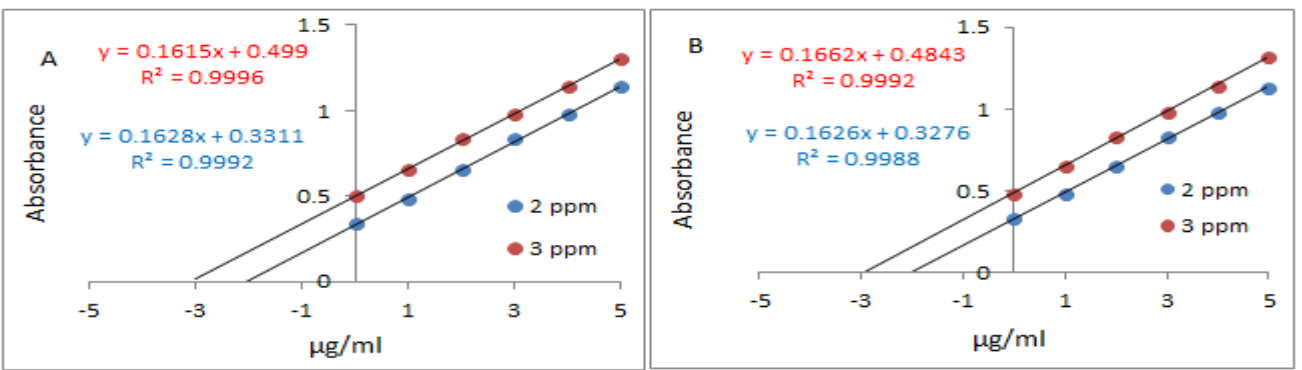

الثكل 10: منحنيات الاضافة القياسية للسيفوتاكسيم صوديوم في مستحضراته الصيدلانية

A : هندي المنشأ B: تركي المنشأ 
Journal of Education and Science (ISSN 1812-125X), Vol: 29, No: 3, 2020 (11-31)

الجدول 9: مقارنة دقة الطريقة المقترحة للمركبات الدوائية في المستحضرات الصيدلانية مع طريقة الاضافة القياسية

\begin{tabular}{|c|c|c|c|c|}
\hline \multirow{2}{*}{ Pharmaceutical preparation } & \multirow{2}{*}{ Certified value } & \multirow{2}{*}{$\begin{array}{l}\text { Amount present } \\
\qquad(\mu \mathrm{g} / \mathrm{ml})\end{array}$} & \multicolumn{2}{|c|}{ Drug content found (mg) } \\
\hline & & & $\begin{array}{l}\text { Present } \\
\text { method }\end{array}$ & $\begin{array}{c}\text { Standard } \\
\text { addition }\end{array}$ \\
\hline \multirow{2}{*}{ Cefex Capsules India } & \multirow{2}{*}{$500 \mathrm{mg}$} & 2 & 515.85 & 513.21 \\
\hline & & 3 & 515.50 & 495.83 \\
\hline \multirow{2}{*}{$\begin{array}{c}\text { Cephadar Forte Capsules } \\
\text { Jordan }\end{array}$} & \multirow{2}{*}{$500 \mathrm{mg}$} & 2 & 502.60 & 507.90 \\
\hline & & 3 & 507.25 & 505.32 \\
\hline \multirow{2}{*}{ Ceftriaxone vial Spain } & \multirow{2}{*}{$1 \mathrm{~g}$} & 2 & 1.028 & 1.021 \\
\hline & & 3 & 1.011 & 0.992 \\
\hline \multirow{2}{*}{ Triaxone vial Saudi Arabia } & \multirow{2}{*}{$1 \mathrm{~g}$} & 2 & 1.014 & 0.989 \\
\hline & & 3 & 1.020 & 1.001 \\
\hline \multirow{2}{*}{ Brucitaz vial India } & \multirow{2}{*}{$1 \mathrm{~g}$} & 2 & 0.971 & 1.016 \\
\hline & & 3 & 1.005 & 1.029 \\
\hline \multirow{2}{*}{ Deforan vial Turkey } & \multirow{2}{*}{$1 \mathrm{~g}$} & 2 & 0.962 & 1.007 \\
\hline & & 3 & 1.002 & 0.971 \\
\hline
\end{tabular}

*Average of five determinations

الاستتتاجات

تم اقتراح طريقـة طيفيـة غير مباشرة باستعمال نظـام تفاعل N-بروموسكسينميد وصبغة ايفانز الزرقاء في وسط حامض الهيدروكلوريك. إذ كانت الطريقـة ذات انتقائية وحساسية عالية، كما تميزت بالبسـاطة كونها لا تحتاج الى تتظيم الدرجـة الحراريـة وخطوات الاستخلاص ولا تعـاني من تداخلات مـواد السواغ في التقدير • وطبقت الطريقـة بنجـاح على المستحضـرات الصسيدلانية للمركبات المدروسة بدقة وتوافق جيدين، فضلاً عن كونها متفقة احصائياً مع طريقة الاضافة القياسية.

المصادر

1. Bothara S. S., Kadam K. R. and Mahadik K. G., "Antibiotics". 14th ed. Principles of Medicinal Chemistry. Pune: Nirali Prakashan. p. 81 (2006).

2. Khan M. N., Ahmad J. and Jan M. N., J. Braz. Chem. Soc., 27:912-918. (2016).

3. British Pharmacopeia, CD-ROM. London, The Stationery Office Ltd., Norwich NR3 1GN (2013).

4. Liang X. Y., Zhong Y. J. and Liu Z. M., Yixue Zongshu. 20:1080-1082 (2014).

5. Naimi H. M., Rasekh H. and Yousofi H., BMC. Res. Notes, 9:86 (2016).

6. British pharmacopoeia, The stationary office London. Vol I. pp.423,666-667 (2007).

7. Chen D., Wang H. and Zhang Z.,In Spectrochim. Acta. A Mole. Biomol. Spectrosc., 78:553-557 (2011). 
8. Irandoust M., Shariati-Rad M. and Khodabakhshi M., Int. J. Pharm. Sci. Res., 5:97-103 (2014).

9. Kumar CH. A, Gurupadayya B. M. and Sloka S. N., T. J. Pharm. Res.,10:81-88 (2011).

10. Kumar H. A., Kumar T. A. and Gurupadayya B. M., , Scholar Res. Library, 2:278-287 (2010).

11. Pasha C. and Narayana B., Eclet. Quim., 33: 41-46 (2008).

12. Jugade R. and Keskar M., pharm. Anal. Acta., 6:360-366 (2015).

13. Al-Kahdimy A. S. H. and Ahmed M. A., Baghdad Sci. J., 13:480-488 (2016).

14. Hassan R. O., , Chem. Sci. Trans., 2:1110-1117 (2013).

15. Khan M. N., Kalsoom S. and Hussain R., Pak. J. Anal. Environ. Chem., 17:118-123 (2016).

16. Feier B., Gui A. and Cristea C., Anal. Chem. Acta., 976:25-34 (2017).

17. Zhao X-J., Li Y-Q. and Bal W-D., China. J. Anal. Chem., 44:1927-1933 (2016).

18. Feier B., Blidar A. and Pusta A., Biosensors, 9:1-17 (2014).

19. Alfeen A. and Elias B., Chem. Mater. Res., 7:66-73 (2015).

20. Rao A. L., Prasanthi T. and Spandana U. S., Int. J. Res. In AYVSH Pharm. Sci., 1:137-146 (2017).

21. Jeswani R. M., Sinha P. K. and Topagi K. S., Int. J. Pharm. Tech. Res., 1:527-536 (2009).

22. Ilyas S. A., Imran M. and Kumar N., Int. J. Pharma. Sci. Res., 6:5164-5173 (2015).

23. Roopa K. P. and Jayanna B. K., Anal. Chem. Lett., 6:143-152 (2016).

24. Qian Y. J., Pan X-P. and Yixing J., Chin. J. Anal. Lab., 5:470-480 (2012).

25. Nkeoma N. O., Godwin I. C. N. and Nkechinyere U., Sci. Res. Academ., J., 2:342-347 (2007).

26. Pranitha G. and Venkateshwavlu G., World J. Pharm. Pharm. Sci., 5:2249-2260 (2016).

27. Zhang D., Ma Y. and Zhou M., Anal. Sci., 22:183-186 (2006). 
28. Aleksic M. M., Lijeskic N. and Pantic J., Facta Uni. Ser. Phys. Chem. Tech., 11, 55-66 (2013).

29. Solangi A., Memon S. and Mallah A.,Turk. J. Chem., 34:921-933 (2010).

30. El-Bagary R. I., Abo-Talib N. F. and El-Hakeem M. M., Curr. Pharm. Anal., 14, 461-474 (2018).

31. Bhagyasree A. L., Kiran B. S. S. and Muneer S., J. Pharm. Res., 11:522-524 (2017).

32. Gaudin K., Langlois M- H. and Kauss T., Pharm. Anal. Acta., 6:1-5 (2015)

33. Frag E. Y., Mohamed G. G. and Farag A. B., Insight Pharm.Sci.,1:47-54 (2011).

34. Sayed R. A., Hassan W. S. and El-Mammli M. Y., Orient. J. Chem., 28:639-650 (2012).

35. Al-Awadie N. S. T. and Ibraheem M. H., I.J.R.P.C., 6:891-909 (2016).

36. Zhang F., Gu S. and Ding Y., J. Elec. Chem., 698:25-30 (2013).

37. Arbianto A. D., Rahayu M. D. and Kusumaningrum S., R.J.P.B.C.S., 8:22-29 (2017).

38. Arafat M., Golocorbin- kon S. and Mikov M., Int. J. Pharm. pharm. Sci., 7:343-346 (2015).

39. Saranya C. H. L., Thejaswini J. C. and Gurupadayya B. M., I.O.S.R. J. pharm., 4:12-18 (2014).

40. Tambe Y. B. and Kothari S., Int. J. Sci. Res., 5:1847-1851(2016).

41. Yao L., Xue X. and Chen F., Contrast Media Mol Imaging, 2018:10 (2018).

42. Smith S. J., Horstickand E. J.and Dowling J., J. Vis. Exp., 30:105 (2015).

43. Jiang Eb- H., Liu S. P. and Hu X. L., Chinese J. Anal., 31:1053-1057 (2003).

44. Qin Eb-Z. H., Fan L. and Liu S. P., Chinese J. Anal., 30:1486-1489 (2002).

45. Ravisankar P., Navya C. N., Pravallika D. and Sri D. N., JOSRJ. Pharm., 5:7-19 (2015).

46. Inam-ul-Haque, Hussain S. A. and Aslam N., Sci. Int. (Lahore), 19:111-123 (2007). 